\title{
Conocer y conocerse a través del teatro
}

\author{
Know and know yourself through theater
}

\author{
Maria Lucia Pollio \\ Uniiversità degli studi di Napoli Federico II (Italia) \\ Departamento Sociología \\ marialucia.pollio.11@gmail.com
}

Recibido 20/02/2018

Aceptado 29/05/2018
Revisado 29/05/2018

Publicado 01/07/2018

\section{Resumen}

El teatro, arte total por excelencia, nació con el ser humano por su natural necesidad de expresarse y de comunicar. Desde entonces sigue desarrollándose con él, volviendose en un efectivo espejo de la sociedad. Actualmente muchos son los espacios que ofrecen talleres de teatro para todas las edades y fue precisamente a partir de un taller en el cual participé que empecé a reflexionar sobre lo que ese arte aporta a las personas.

Estableciendo el objetivo de profundizar sobre las características intrínsecas del teatro, a través de una entrevista realizada a dos chicas estudiantes de psicología que participaron en el taller y la lectura

\section{Abstract}

The theater, total art for excellence, was born with the human being by his need to express himself and communicate and it continues to develop with him. It is, in fact, the mirror of the society. Currently, there are many schools of theater for all ages and It was one of these workshops in which I participated that I started to reflect on what that art brings to people.

The aim of the research is to investigate in deep the inherent characteristics of the theatre through the interview with two students of psychology who took part to the theater class as well as to the reading of specialist book for

Para citar este artículo

Pollio, Maria Lucia (2018). Conocer y conocerse a través del teatro. Tercio Creciente, 14, págs. 65-76.

https://dx.doi.org/10.17561/rtc.n14.5 
de libros escritos por profesores del sector, he podido observar y concluir que el teatro es un arte fundamental para el desarrollo individual de las personas y es una eficaz herramienta educativa.
Professors of this field. It was possible to conclude that theatre is a fundamental art for the personal development and it can be successfully used as educative tool.

Palabras clave / Keywords

Teatro, educación, actuar, expresión, emociones.

Theater, education, perform, expression, emotions

Para citar este artículo

Pollio, Maria Lucia (2018). Conocer y conocerse a través del teatro. Tercio Creciente, 14, págs. 65-76.

https://dx.doi.org/10.17561/rtc.n14.5 


\author{
"Interpretar requiere mucho esfuerzo, \\ Pero en el momento en que lo consideramos un juego, \\ Deja de ser trabajo. \\ Una obra de teatro es un juego" \\ (Peter Brook, director teatral y cinematográfico)
}

\section{Introducción}

El teatro, una de las artes más antiguas, es una necesidad primordial de expresión que acompaña a los hombres de todos los tiempos, y aunque se ha modificado con la sociedad y ha revolucionado su cara y protagonistas, nunca ha desaparecido.

Casi todos, a lo largo de la vida, hemos tenido una cita con este arte, ya sea actuando en un teatro, yendo a ver una obra, jugando en un oratorio, imitando a nuestros héroes o participando en un taller extra-escolar.

Muchas son, al mismo tiempo, las contradicciones que este arte lleva consigo; elogiada y criticada, herramienta de sátira social o técnica de terapia psicológica, trabajo para los más audaces y un juego educativo para muchos.

El tema central del siguiente estudio de caso es la metodología de trabajo del arte teatral, en cuanto que las técnicas utilizadas por el teatro tienen como propósito el trabajo sobre y con las emociones y los sentimientos de las personas.

Propiciado por su característica intrínseca, el teatro resulta una herramienta del todo eficaz para la educación a todos los niveles.

El objetivo principal de mi trabajo es el de profundizar las características del trabajo del arte teatral, poniéndome como objetivos específicos los de analizar la validez del teatro como herramienta de trabajo personal y la necesidad de introducirlo en la educación.

Mi reflexión empezó cuando participé en un taller de teatro de cinco días impartido en la universidad de Jaén.

Las clases comprendían ejercicios de calentamiento corporal, vocal y de expresión, trabajo sobre las intenciones, construcción de relatos, improvisación y análisis de una obra, de su estructura y estudio de los personajes, con el fin de una puesta en escena.

El corazón de la práctica teatral, de hecho, es la personificación de un sujeto teatral que espera la persona física del actor para nacer y crecer. El actor asumirá sus peculiaridades gestuales y vocales, iniciando con el imaginar su vida y acabando viviéndola por toda la duración de la representación.

Al finalizar el taller, a cada uno de nosotros se nos fue preguntado una opinión general sobre el trabajo hecho y una chica, estudiante de psicología de la universidad, afirmó que había descubierto más sobre si misma que en cualquier otro curso de los que había participado en relación con las emociones. 
Así que pensé sobre mi experiencia y la de las personas encontradas, medité en lo que a mí me aporta el teatro y los retos que cada vez más me ayuda a superar.

La puesta en escena, la representación en sí misma, es solo la parte final de un recorrido que enriquece más de lo que se puede imaginar.

"El hecho teatral va más allá de la escritura dramática, porque la representación de los papeles sociales, reales o imaginarios, provoca una participación que ninguna otra parte puede provocar". (Duvignaud Jean, 1981, p. 14)

Pienso que, entre las artes, el teatro es un medio fundamental para reconocerse a uno mismo y conocer a los demás, aprender a expresar las emociones y vencer los bloqueos más escondidos.

Especialmente en la sociedad actual, donde el estilo de vida es mucho más frenético, donde se han multiplicado los estímulos auditivos y visuales y el nivel de estrés neuro-físico diario sigue creciendo, es más fácil olvidarse como se juega, como se sonríe o como se habla sencillamente mirándose en los ojos.

Sobre todo en una sociedad donde quizá nos han educado en no manifestar todas nuestras emociones en razón a las normas de comportamientos sociales que nos dicen qué cosas son adecuadas hacer y qué cosas evitar y con las cuales, seguramente representaremos el perfil social aceptado por todos.

Es por esta necesidad de volver a expresarse que creo que se han incrementado, en los últimos años, los talleres de teatro para todas las edades y las necesidades, proponiendo, de hecho, una gran variedad de horarios y de sistemas de trabajo.

También pienso que el teatro es una herramienta educativa muy eficaz, en cuanto que ayuda a los individuos a desarrollar capacidades que normalmente no se aprenden en las escuelas.

\section{Metodología}

Para contrastar mis hipótesis, como metodología de recolección de las informaciones, he elegido utilizar un análisis de tipo cualitativo; es decir, entrevistar a dos chicas de psicología que participaron en el taller, no por hacer una comparación entre esa asignatura y el teatro, sino porque considero que por los estudios que hacen tienen más familiaridad al trabajar con las emociones.

Las entrevistas he decidido ponerlas en el texto indirectamente, junto a la documentación teórica que apoya la investigación, la cual comprende asuntos de sociología del teatro, de arte teatral y de enseñanza a través del teatro.

He elegido la entrevista como metodología de análisis ya que pienso que es una de las técnicas más apropiadas en los casos en los cuales se necesita hablar sobre experiencias de vida muy personales y sobre los sentimientos.

La entrevista, de hecho, permite acceder al plano emocional de los individuos, obteniendo informaciones acerca de percepciones, valores, creencias, opiniones, sentimientos y motivaciones. Es decir, permite profundizar en contextos no fácilmente accesibles, enriqueciendo la investigación.

Es una técnica, también, que requiere tiempo y un minucioso trabajo de análisis e interpretación del contenido de la entrevista.

Necesita un oportuno conocimiento del asunto por parte del entrevistador, el cual tiene que saber a quién entrevista, como acceder a esas personas, cuantas veces entrevistarlas y cómo interactuar con ellas. Es aconsejable tener empatía y discreción a la hora de suministrar las preguntas.

Una entrevista puede ser, a nivel técnico, estructurada (cuando se sigue un guión establecido y no es permitido divagar), semiestructurada (cuando hay una guía de preguntas flexibles a modificaciones) y abierta (donde se tiene solo una orientación general sobre el contenido). 
Yo he optado por una entrevista semiestructurada, redactando previamente todas las preguntas, dejándome, en cambio, la libertad de modificar el orden de las mismas y de agregar y modificar algunas a lo largo de la entrevista.

Quedé con las dos chicas en la biblioteca de la universidad, en la planta alta donde hay grandes ventanas desde las cuales entra el sol. Mi objetivo era de transmitir, de la mejor manera posible, confianza y tranquilidad, intentando convertir la entrevista en una sencilla charla entre personas que aman el teatro y que han compartido unas maravillosas experiencias juntas.

A lo largo de la entrevista puse, también, ejemplos de mi vida e incluí otras preguntas de descompresión.

Antes de empezar, expliqué la motivación y la finalidad de la entrevista, contando a las chicas por qué decidí escribir el artículo sobre el taller de teatro y por qué me puse en contacto con ellas en específico. Les pregunté si estaban de acuerdo en que realizara grabaciones de voz y posteriormente utilizar sus palabras en el artículo.

El guión de preguntas que redacté estaba así estructurado:

1. ¿Cómo te llamas y de dónde eres?

2. ¿Cuál es tu campo de estudio?

3. ¿Lo que estudias está muy relacionado con el teatro?

4. ¿Siempre has tenido interés hacia el teatro? ¿Por qué?

5. ¿Por qué quisiste hacer el taller?

6. ¿Qué has aprendido y que te aportó el taller?

7. ¿Es importante, para ti, introducir el arte teatral en la educación? ¿Por qué?

Después hice la entrevista y transcribí cuidadosamente todo lo grabado. Así seleccioné las partes más significativas y las coloqué en el trabajo a modo de explicación y apoyo a la investigación.
Para organizar el material y ordenar los temas objeto de estudio, he dividido el trabajo en pequeños capítulos: El arte teatral, El trabajo sobre las emociones, Teatro y enseñanza, La comunicación y Conclusiones.

\section{El arte teatral}

"El arte teatral no es el arte de la actuación
del actor, ni de la obra teatral, ni de la
representación escénica, ni del baile (...)

Es el conjunto de elementos que componen estos distintos campos"(Daniel Craig, actor)

La palabra "teatro" deriva del verbo griego $\theta \varepsilon \bigotimes \sigma \theta a ı$ (theâsthai) y significa "mirar"; formalmente "el lugar desde donde se mira".

En el diccionario de la Real Academia Española se encuentran varias definiciones de la palabra "teatro", entre las cuales:

- Edificio o sitio destinado a la representación de obras dramáticas o a otros espectáculos públicos propios de la escena (del latino theātrum y del griego $\theta \varepsilon ́ a t p o v$ théatron).

- Sitio o lugar en que se realiza una acción ante espectadores o participantes.

- Arte de componer obras dramáticas o de representarlas.

- Acción fingida y exagerada.

La infinita riqueza de formas y de tradiciones teatrales a lo largo de la historia vuelve difícil una definición general del arte teatral.

Se puede decir que nace con el ser humno por la necesidad de expresión desde el interior hacia el exterior, aunque su origen tenía mucho más una función ritual y religiosa de la que tiene ahora.

“El teatro es bastante más que el teatro. Es un arte. Sin duda la más antigua de todos, pero es 
un arte enraizado, el más comprometido de todos con la trama viviente de la experiencia colectiva y el más sensible a las convulsiones que desgarran una vida social. El teatro es una manifestación social" (Duvignaud Jean, 1981, p.13)

Es una manifestación social porque está estrechamente involucrada en los acontecimientos que rodean a la sociedad de cada época.

Así que, desde los rituales tribales para pedir favores a las divinidades y agradecerles los dones de la naturaleza, se pasa por el teatro griego con su grandes autores de tragedias y comedias, para ir a la Antigua Roma, donde el teatro estaba finalizado al ocio de la población, y por fin el teatro religioso del Medioevo, el Renacimiento con la Comedia del arte y el Siglo de Oro, que tiene como protagonistas todas las capitales artísticas europeas y sus cortes, desde las cuales se llega a las grandes transformaciones del mundo teatral.

En el 700' hay una revolución de los edificios teatrales y un nuevo público, la burguesía, que paga para poder acceder al espectáculo. El 800 ' con sus obras románticas prepara a los cambios que ocurrieron en el siglo XIX, cuando se revolucionó el trabajo del actor y la puesta en escena. Directores y actores como Tadeusz Kantor, Peter Brook, Jerzy Grotowski, Eugenio Barba, Mejerchol'd y Stanislavskij, crearon nuevas escuelas y nuevos estilos de recitación y de trabajo sobre los actores.

Desde finales del siglo $X X$, con el teatro del absurdo, que nace desde la posguerra, se desarrollan las corrientes más contemporáneas y experimentales.

Actualmente el panorama teatral es más variado que nunca; obras de teatro antiguo se alternan a representaciones provocadoras u obras clásicas se revisan en llave contemporánea, musicales, espectáculos históricos, visitas guiadas teatralizadas, improvisaciones; cada sitio se puede volver en un teatro y las propuestas cambian de continuo, respondiendo a necesidades estéticas y sociales siempre nuevas.
"El hecho teatral va más allá de la escritura dramática, porqué la representación de los papeles sociales, reales o imaginarios, provoca una participación que ninguna otra arte puede provocar. La creación dramática de ningún modo se libra de esta exigencia; el dramaturgo anima por medio de la palabra a personaje cuya expresión exige la realidad visible. Es la representación de la imagen del hombre social" (Duvignaud Jean, 1981, p.14)

Sea cual sea la época, los rasgos característicos de esa arte quedan casi igual: presentar una acción a través de los actores que encarnan y muestran determinados personajes a un público que está reunido en un espacio y un tiempo organizado para recibirlo.

Cada obra teatral, más o menos, se compone de un texto (hecho por acciones y conflictos), de los actores, escena, espectadores y toda una parte más técnica que comprende escenografía, luces, sonidos y vestuario.

¿Para representar una historia, desde dónde se mira? En este sentido se puede sentir que la vida real parece ser la fuente mayoritaria de inspiración por los artistas, empezando desde lo que rodea las personas y lo que estas llevan dentro.

Lo que se verá en la escena será la sociedad tal cual la conocemos, con su conflictos y sus rasgos y, por supuesto, el ser humano y su vida interior.

Si se intenta preguntar a los actores o a cualquier individuo que practica teatro por qué lo practica, porque le gusta ese arte, las respuestas casi seguramente serán muy varias y algunas veces las mismas personas tendrán dificultad en concretar los pensamientos en palabras.

"Es algo que me encanta porque no puedo explicarlo [...] me gusta porque cuando yo veo una persona que está viendo una obra, veo en su cara la emoción que le hace sentir, cuando el público conecta con esa arte es una sensación que no sé explicar, me pongo nerviosa hasta recordarlo, pero 
es algo que no sé explicar y por eso me gusta. El teatro para mí es perfectamente caótico." afirma Belén J., en el momento en el cual, durante la entrevista, le pregunté en referencia a su pasión por el teatro.

Es algo que "no se puede explicar" porque creo que es algo que está fuertemente unido a las emociones más profundas del hombre y es cuando se necesita expresarlas que se exige también el arte teatral.

\section{El trabajo sobre las emociones}

\begin{abstract}
"El hombre sensible obedece a los impulsos de la naturaleza y no lanza más de un grito que le sale del corazón; cuando templa o fuerza ese grito, ya no es él, es un comediante que actúa". (Denis Diderot, escritor y filósofo)
\end{abstract}

Tomando como ejemplo la división efectuada por Pere J. Mascaró en su obra de teatro "Teatro, el arte de la enseñanza" (2001, p.11) sobre las áreas en las que se divide el trabajo teatral, observándose que un taller comprende diferentes secciones de trabajo:

- Contacto y grupo; donde se plantean ejercicios que tienen como objetivo que el grupo funcione bien y que sus miembros construyan buenas relaciones entre ellos, que se sientan cómodos en el espacio escénico y con los demás.

- Voz; empezando por la respiración y los ejercicios vocales y de dicción, se toma conciencia del funcionamiento del aparato fonorespiratorio.

- Texto; se estudian los textos teatrales, de los cuales se analiza la historia, la estructura, los conflictos, los personajes, las intenciones y las palabras claves.

- Cuerpo y movimiento; comprende ejercicios focalizados en tomar conciencia de las distintas partes del cuerpo para ganar un equilibrio y coherencia entre lo que se hace y lo que se dice, para que el mensaje llegue al público de forma completa.

- Improvisación y técnica teatral; comprende ejercicios en grupo, en pareja o de monólogos donde, a partir de unas indicaciones básicas, se desarrollan las escenas.

- Historia del teatro; es necesaria para comprender en profundidad el guión y los personajes que se van a interpretar.

Estas secciones, en líneas generales, forman una multitud de ejercicios que componen los talleres de teatro, los cuales, a según del director, tendrán una determinada postura y focos de estudio.

En el caso específico del taller como objeto de estudio, eje del trabajo fue lo de preparar algunas escenas en pareja, de la obra "Casa de muñeca" de Henrik Ibsen. A cada pareja fue entregado un diálogo, que debió estudiar y memorizar, eligiendo también el vestuario y el maquillaje del personaje asignado.

Antes de pasar a la práctica tuvimos que leer toda la obra, contextualizarla históricamente y analizar, con la ayuda del director, los personajes y los conflictos que habían entre ellos, preguntándonos en cada personaje que objetivo tiene hacia el otro y por sí mismo.

Fue a la hora de actuar, que cada uno de nosotros se enfrenté con sus debilidades, bloqueos y capacidades; y no sobre la obra, sino, sobre sí mismo.

Dificultad sobretodo en el expresarse y exteriorizar lo que lleva dentro, como se puede constatar en las palabras de Belén J. Y Pilar M., durante la entrevista, al respecto de sus experiencias.

"Fue una semana que aprendí mucho más de mí misma y de la gente que estaba allí que en cualquiera de los otros cursos que yo he hecho. Creo que no he salido con tantos conocimientos 
como con el curso de teatro [...] Yo por ejemplo lo que he aprendido con el ayuda del director fue que me cuesta mostrar las emociones, hay emociones que son básicas, todo el mundo muestra alegría, pero que a la hora de expresar relaciones más íntimas, como en una relación amorosa o expresar ira, cabreo, son cosas que necesitan más cofinancia con la persona, pero que también son emociones, igual que el resto y que es necesario mostrarlas,; entonces he aprendido que no hay emociones ni positivas ni negativas sino que varían de intensidad pero que no tienen ningún sesgo negativo o positivo y que es necesario aceptarlas, normalizarlas, porque esto contribuye a que tenga un equilibrio contigo y con la sociedad." (Pilar M.)

"Personalmente me costaba muchísimo expresar emociones, no es que ahora después del taller soy la mejor persona mostrando emociones, pero es verdad que en mi caso yo siempre era una de esas personas que <<muestra alegría, mostrarte alegre con los demás, los demás no tienen culpa si tu estas mala o bien $>>y$ esa necesidad de que todo el mundo me está viendo bien aunque yo por dentro me sienta vacía, o que no me encuentre bien ni conmigo misma ni con el resto; $y$ a partir del taller me he tomado unos minutos para mí misma para reflexionar y decirme <<oye escúchame, si realmente no estas contenta o no estás bien, o yo que sé, no quieres encontrarte con esa persona o no quieres seguir en esta carrera por ejemplo, piénsalo y haz las cosas consecuentemente, el mundo no tiene que verte siempre con una sonrisa. Si tienes que estar un día mal, llorar y cerrarte en tu cama, no salir todo el día, pues hazlo, si tienes que reflexionar para seguir adelante, siegues con ello, pero que tu actitud siempre corresponda con las emociones que sientes. No tenga una actitud falsa de la vida, porque esto no te va llevar a ninguna parte. >>"(Belén J.)

Volviendo a mi experiencia del teatro, en el momento de dar vida a un personaje, se nos preguntó: ¿Qué está pensando ahora tu personaje? ¿Qué quiere? ¿Qué siente? ¿Cómo se mueve?

Pensar todo esto mientras debes intentar escuchar a tu compañero, conectar con él y respetarlo y, además, ponderar el espacio escénico, para no cubrir a quien está contigo en escena y hacerte ver por los espectadores.

Es así que se choca con las dificultades de expresar sentimientos; ira, ternura, enfado, despecho, etc., parecen sencillos en cuanto hacen parte espontáneamente del día día; pero, si el personaje siente odio y la persona que debe representarlo tiene dificultad en expresar sentimientos negativos hacia los demás, es aquí que sale fuera el obstáculo.

"Tienes que conocerte primero a ti mismo y después conocer a tu personaje para poder abordarlo; y de la psicología más viene solo quedarte y de conocerte a ti misma. Pero creo que sería interesante para muchas de las técnicas que usan en psicología, el meterte en otro personaje, eso te obliga a ti mismo conocerte a ti mismo, a ver cómo te sientes, y viendo distintas experiencias creo que te ayuda a ti mismo como persona." (Belén J.)

Otra dificultad de la practica teatral se refiere al deber escuchar activamente a las otras personas, para saber cuándo hablar, para ayudar a un compañero que se ha olvidado unas frases y porque, en la vida real, no sabemos ya lo que la otra persona va a decir y en consecuencia, escuchamos atentamente.

Además, es fundamental ser siempre reactivos y poner energía en cada parte del cuerpo: es lo que los espectadores ven y en relación a esa energía pondrán más atención en lo que se realiza en el escenario.

Será la misma representación de los conflictos y de los desgarramientos que afectan el hombre en el escenario, que nos puede liberar.

Todo este trabajo sobre una obra y sobre los personajes "Si lo aplicas a ti mismo. Es un choque" (Belén J.), y así nacen retos y nuevos conocimientos.

Cofiancia en nosotros mismos, compromiso con el grupo, trabajo compartido, expresión a todos los niveles (corporal, gestual y oral), creatividad, 
diversión, son algunas de las cosas que el teatro aporta a quien se atreve en este arte.

\section{Teatro y enseñanza}

"Quien mueve el cuerpo, mueve el corazón; Quien mueve el corazón, mueve las emociones; Quien es capaz de emocionarse y quien es capaz de emocionar ha encontrado la llave del misterio- milagro de la educación" (Carlos Pons, coreógrafo)

En virtud de las propiedades intrínsecas del trabajo teatral, considero importante la incorporación del mismo en el sistema escolar.

Las artes, en cuanto medio y herramienta de expresión, son también un medio de conexión con las realidades circunstantes, haciendo posible la reinterpretación de las mismas y potencian las capacidades existentes en aquellas personas que las practican.

Es decir, las artes son una eficaz herramienta para el desarrollo vital e intelectual de las personas, y si los niños son los que construirán el futuro, desarrollar determinadas características puede ser esencial.

Entre el teatro y la educación hay una relación muy antigua, no obstante la valoración de este vínculo está marcada por una dialéctica que va desde la aprobación al rechazo. Si da una parte el adjetivo "educativo" viene atribuido con frecuencia al teatro, varias de sus exhibiciones son consideradas inmorales.

El interés en el presente estudio es el teatro considerado como posibilidad e instrumento de libertad, un territorio diferente donde poder aprender jugando.

"yo creo que dentro de la misma asignatura de educación física, que es tiempo de relax, de hacer deporte. Yo por ejemplo odiaba esa asignatura, siempre porque he sido una niña gordita y me costaba mucho trabajo hacer las cosas, ningún niño quería jugar conmigo y era como un poco tétrico para mí, era un pequeño trauma esa hora. Sin embargo pienso que si hubiera una asignatura en la que ya no solo se mira a las capacidades físicas así como tal, fuerza, elasticidad, velocidad, sino también expresión artística y expresión corporal, sería positivo para los niños porque los ayudaría a entender cosas como qué es la inteligencia emocional, comprender sus propias emociones, las emociones de los demás, con esto que dijo Pilar del role playing. Lo que es en si el teatro es saber meterte dentro otro personaje, de empatizar con un contexto distinto del tuyo, así que por el cuándo ves un amigo tuyo que está mal, entender porque está mal, y como puedes ayudarlo verdaderamente, que no es como si estas Ilorando decir<<porque no Ilorar, no estar mal>> porque en verdad a nos cuesta ver que las personas están mal, muchas veces esas personas necesitan llorar, necesitan tener una catarsis emocional y a partir de allí, una vez que han tocado el fondo, volver a subir. Pero si tú estás mal, lo reprimes y no llorar y el día siguiente vuelves a sonreír y sigues estando mal al final entras en un bucle en un vacío, las emociones no la expresas y te acaban ahogando. Necesitamos expresar, y hacerle a los niños entender que las emociones están allí, que hay que comprenderlas, que hay que expresarlas, que no hay que tener miedo de lo que somos, de lo que queremos, de lo que sentimos. Yo creo que es muy importante."(Belén J.)

"Sino sobre todo en el colegio, en sitios donde los niños son más pequeños y están empezando a formar sus inquietudes, sus emociones, al final la regulación de las emociones y la expresión de las mismas es una herramienta que te ayuda a comunicar con tu entorno y seguramente esos niños tengan más facilidades para desarrollar su actividades con el resto de los niños, eso.

Pensamos que la disciplina artística que más puede influir en el mejor desarrollo de las emociones es el teatro [...] aquí en el colegio se hace como actividad extraescolar, no entra en el programa educativo, sobre todo en España las materias que tienen que ver con la cultura, música, plástica, filosofía incluso, como que le dan menos importancia, y cada vez les están quitando más." (Pilar M.) 
"A mí me han llegado compañeras que me han dicho que en segundo bachiller han puesto psicología al puesto de filosofía, y memoria, aprendizaje, la parte de la inteligencia emocional viene súper poco. A nivel de estructura cerebral puede ser interesante pero en su día día no creo que le sirve para nada."(Belén J.)

En parte, la escuela ha dejado de ser un espacio para el conocimiento, los objetivos de los docentes es instruir en las herramientas de lectoescritura y cálculo, dejando de lado las asignaturas que ayudan a fomentar las capacidades de crear.

Y si la función de las escuelas es crear un espacio para el desarrollo de cada una de las personas que la viven, el teatro debería ser parte esencial en este camino.

Pero como afirmé antes, la relación entre educación y teatro es remota y como explica Maria Giacobbe Borrelli en el artículo "Sconfinati corpi: sull'uso del teatro per insegnare l'italiano ai ragazzi migranti" (2010), ya en la prehistoria el teatro tenía también sesgos educativos. La performance primitiva con su carácter ritual-religioso, difundía creencias y valores, ofreciendo, a través de sus narraciones, los elementos para la formación social y personal.

En la antigua Grecia las tragedias y comedias representadas tenían una función educativa tanto en el contexto religioso cuanto político-social. Además la cultura greca fue ejemplo de escuela y democracia también a través de sus obras teatrales; obras que hoy en día se siguen representando.

En el Medioevo el carácter educativo del teatro fue extendido a la educación cristiana; de hecho, las representaciones de la Biblia tenían el objetivo de instruir moralmente al pueblo.

En el Renacimiento nacen dos importantes modelos: el teatro en los colegios de los Jesuitas, para aprender las obras clásicas, el arte oratoria y favorecía la introducción de los idiomas nacionales en la escuela, Filippo Neri utiliza las actividades artísticas, canto y música sobre todo, para la educación de los jóvenes.
En el siglo XIX otro gran ejemplo educativo es Giovanni Bosco, el cual se ocupó de la educación ético-moral de los jóvenes a través del juego, música y teatro. Su oratorio quería ser una alternativa a la vida difícil de muchos jóvenes procedentes de las clases con más dificultades sociales.

Los contenidos de sus trabajos variaban desde las historias de la Biblias y biografía de los Santos a la adecuación de obras literarias e historias donde los personajes enfrentaban los problemas que se referían a las nuevas unidades de mesura o al sistema métrico decimal.

En Inglaterra nace el "Drama en education", gracias al trabajo de Harriett Finlay-Johnson, que utilizaba el drama para ayudar los niños en el aprendizaje de las disciplinas escolares y en su crecimiento en el grupo de sus coetáneos, y a Henry Caldwell, que se servía de la recitación en clase para profundizar el estudio de las obras literarias junto al objetivo de desarrollo personal y social de los jóvenes.

Peter Slade que, empezando por el juego creativo, dejaba total libertad de expresión y acción a los niños, para contrastar la poca libertad que les dejaban los adultos.

Desde la posguerra hasta los años setenta comenzaron a existir diversas reformas en las escuelas de muchos de los países de Europa, introduciendo también el teatro en la didáctica.

Por el reconocimiento de los efectos terapéuticos de la técnica teatral, el teatro fue siempre más empleado en la psicología y nacieron actividades como la danzaterapía y la dramaterapía.

En el último siglo el teatro ha sido coadyuvado por los nuevos medios de comunicación (cine, televisión e internet) que han modificado las relaciones sociales, la comunicación entre los individuos $y$, sobre todo, la manera de organizar el trabajo en las escuelas. 
Propio por esa propagación siempre más intensa de los medios de comunicación en la vida diaria, es más urgente la validación del arte teatral como instrumento educativo y la difusión del mismo entre la población más joven.

Importante ha vuelto llevar la clase a teatro (un ejemplo son las matinées) previo estudio de la obra tan antes cuanto después la visión, analizando el contexto histórico, los personajes y las temáticas desarrolladas.

También hay iniciativas dirigidas a conocer las profesiones teatrales, a través de la producción de una obra que no tiene como finalidad la puesta en escena en un teatro, pero que lleva el objetivo responsabilizar y quizá, cultivar nuevas pasiones.

Y si todo este trabajo no es desarrollado en las escuelas, se han llevado a cabo en otras zonas educativas como los talleres y workshop florecidos en estos últimos años.

\section{La comunicación:}

\section{"El teatro representa la comunicación humana, por lo tanto comunica acerca de la comunicación a través de la comunicación" (Osoboe Mnenie, artista musical)}

Otro pequeño aspecto del teatro que me interesa considerar, porque está estrechamente relacionado al tema de las emociones, es la comunicación.

El lenguaje teatral está compuesto por lenguaje verbal y lenguaje expresivo, corporal y musical. Se descubre así todo el potencial que cada uno tiene en sí mismo, aprendiendo maneras de comunicar que pueden parecer nuevas solo porque no estábamos acostumbrados a utilizarlas.

A través de la práctica teatral, además, se fortalece la relación entre maestro y alumno y entre los alumnos de una clase o grupo teatral. Durante una representación todos son responsables de todos, si un compañero está en dificultad, si ha sido olvidado un objeto de escena, si alguien tiene un problema con el vestido, es tarea de los colegas ayudar a resolverlo, y si no hay buena comunicación el resultado final no será lo esperado.

Consecuencia es el desarrollo de un ambiente de estudio, más dinámico e interdisciplinar, donde los jóvenes sean libres de desplegar su creatividad y natural curiosidad.

\section{Conclusiones:}

Mucho más se podría y se debería escribir sobre este asunto, recercar y profundizar para difundir la importancia educativa de este arte.

Demasiado implantada está la visión del arte teatral solo como "espectáculo", visión debida a una industria cultural que tiene en su mano el poder de difundir la cultura en la sociedad, decidiendo casi por nosotros y solo por beneficios económicos. Además la figura del actor está relacionada al éxito y al dinero, y no siempre al duro trabajo y sacrificio.

Con este trabajo he querido, a través de mi experiencia y la de Belén J. y Pilar M., demostrar lo que aporta el arte teatral en la vida de las personas y argumentar su eficacia en la educación.

Porque sí que el teatro es espectáculo, en cuanto incluye una exhibición y necesita de un público que presencia; pero es también una ceremonia nacida en la prehistoria, es cultura, en cuanto refleja y transmite valores y tradiciones y es arte, resultado de la sensibilidad de los individuos.

El teatro es liberación, es magia en sí mismo y entre actores y público, y sobre todo, es juego, un juego que aprendemos desde pequeños, donde no hay un abismo entre el aprendizaje y el divertimiento, quizá el primer juego del cual necesitan tanto los niños como los adultos. 


\section{Referencias}

Jean Duvignaud, 1981, Sociología del teatro: ensayo sobre las sombras colectiva, México: Fondo de cultura económica.

Maria Giacobbe Borrelli, 2010, "Sconfinati corpi: sull'uso del teatro per insegnare l'italiano ai ragazzi migranti, Rivista di studi di Antropología e Teatro Dossier, Bologna.

Tadeusz Lewicki, 2018, Teatro e educazione, en Franco LEVER, Pier Cesare RIVOLTELLA, Adriano ZANACCHI (ed.), La comunicazione. Dizionario di scienze e tecniche, recuperado en www.lacomunicazione.it el 01/02/2018

Pere J. Mascaró, 2001, Teatro: el arte en la enseñanza, Ciudad Real, Naque ed.

Tomás Moto Teruel y Leopoldo G. Aranda, 2004, Practica de la expresión corporal, Ciudad Real: Naque ed.

Patrice Pavis, 1980, Diccionario del teatro: dramaturgia, estética, semiología, Barcelona, Paidós Comunicación ed., traducción De Toro Fernando 